\title{
Sociedad, paradigmas e intelectuales
}

\author{
Víctor Carranza Elguera \\ Universidad Nacional de Ingeniería \\ vhumberto2014@gmail.com
}

\section{RESUMEN}

Los objetivos de este trabajo son explorar y describir cómo las relaciones sociales sostienen la creación de particulares paradigmas y de sus propios intelectuales. En este sentido, es relevante mostrar situaciones en las que los intereses económicos y políticos de los poderes estatales requirieron del dominio cultural para afianzar la cohesión social. Por tal motivo, se presentan casos históricos que dan cuenta de la relación causal entre religión y moral que, formalizadas a nivel de dogma, inhibieron el desenvolvimiento creativo del conocimiento y, por ende, de la economía y la política. Advertimos que la cultura dogmática, que dominó y sigue dominando el panorama social a nivel global, no pudo evitar las disidencias. En la ruta histórica de esta disidencia, a favor de la razón y la verdad, destacarán herejes, libre pensadores e intelectuales. Una pregunta clave: ¡¿uál es el margen de autonomía de los intelectuales peruanos para recrear los «regímenes de verdad» que devienen hegemónicos en nuestra sociedad?

Palabras Clave: Sociedad, paradigma intelectual, cultura, dogma.

\section{Society, paradigms \& intellectuals}

\begin{abstract}
The objectives of this paper are to explore and describe how social relations sustain the creation of particular paradigms and those of their own intellectuals. In this sense, it is relevant to show situations in which the economic and political interests of the state powers demanded the cultural domain to strengthen social cohesion. For this reason, historical cases, that explain the causal relationship between religion and morality, are presented. These causal relations, formalized at the level of dogma, inhibited the creative development of knowledge and, therefore, the economy and politics. We warn that the dogmatic culture, which dominated and continues to dominate the global social panorama, could not avoid dissidence. In the historical route of this dissidence, in favour of the reason and the truth, heretics will be pointed out, also free thinkers and intellectuals. A key question: what is the margin of autonomy of Peruvian intellectuals to recreate the «regimes of truth» that become hegemonic governments in our society?
\end{abstract}

KEYwORDs: Society, intellectual paradigm, culture, dogma. 


\section{Hegemonía del dogma}

¿Puedes decirme, Sócrates, si la virtud puede ser enseñada? ¿O no puede ser enseñada, sino adquirida por ejercicio? ¿O ni puede adquirirse por ejercicio, ni aprenderse, sino que por naturaleza, o de algún otro modo, sobreviene a los hombres? (Platón, 2003)

Estas preguntas hechas por Protágoras son el parteaguas de la civilización occidental. Imaginemos las comunidades humanas hace miles de años tratando de sobrevivir en medio de tensiones permanentes con el entorno natural, y en un panorama social en el que la lógica de la guerra y el dominio de los más fuertes forjaban sus destinos. Vidas similares para hombres y mujeres que habitaron África, Europa, Asia, Oceanía, América y el macizo andino del Perú.

Hoy sabemos que la clave de la ruta evolutiva de nuestra humanidad se explica por las condiciones materiales y sociales, objetivas y subjetivas, que permitieron el dominio de procesos afincados en la economía, la política y, sobretodo, en la cultura. Eran necesarias competencias en la construcción de herramientas y oficios para el crecimiento económico, y elaborar normas que formalizaran el contrato social; pero, tanto la economía como la política dividían la sociedad en clases y partidos antagónicos. Por ello, resultó imprescindible, crear un mundo de significados, de valores que permitan la cohesión social. Esa es la importancia de la cultura: darle sentido al proyecto humano, afianzar la eficacia de la producción de medios de vida (economía) y la eficiencia en la convivencia social (política), sobre la base de horizontes de sentido.

Pero, en este conflictuado escenario, los límites de los factores que componen la cultura: la moral, el arte y el conocimiento, marcaron, asimismo, los límites fronterizos de la convivencia humana: una moral basada en el dogma religioso, un arte hedonista y un nivel elemental del conocimiento. Por ello, los mediadores más eficaces para sostener la cohesión social fueron chamanes y sacerdotes que promovieron rituales y símbolos vinculados a dioses y demonios, construyendo con ellos una morada de significados morales que, para Carl Jung, es la base de un inconsciente colectivo que hace de la religión, el corazón y el centro de la cultura. Se impuso, a escala planetaria, una moral colectiva afianzada en metáforas como fuentes de sentido, en la fe en seres fantásticos y milagrosos, en narrativas y ritos extraordinarios que prometían atenuar toda angustia terrenal y trascender la muerte. Ello explica la enorme influencia de la iglesia católica en el Perú y la eficacia de sus ritos multitudinarios como la procesión del Señor de los Milagros, en Lima.

He allí la importancia que adquiere, a 465 años antes de la fecha asignada al nacimiento de Cristo, la respuesta a Protágoras por parte de Sócrates cuando este afirma que solo a través de la virtud moral, lograda mediante el conocimiento de la verdad, se alcanza la felicidad. Este llamado a construir horizontes de sentido humano basado en el intelectualismo moral, en oposición al dogmatismo religioso fue, para la civilización 
occidental, el más importante anuncio de un combate que hoy, en el siglo xxI, se mantiene aún irresuelto.

\section{Herejes y libre pensadores}

No obstante la importancia que Jung da a los mitos y arquetipos en la conducta humana, y al esfuerzo de Tomás de Aquino por unir la fe y la razón en un cuerpo doctrinario llamado escolástica (siempre y cuando la razón se subordine a la fe), la necesidad de explicar las causas de los eventos del mundo natural y de la historia social indujo a toda religión a imponerse como dogma, como verdad revelada: el tejido social fue urdido desde religiones que avasallaron el libre albedrío del conocimiento, del arte, de la economía y de la política, y a expresarse, de manera dura y pura, en estados teocráticos.

Este mundo dominado por el dogma no pudo evitar la disidencia. Por un lado, sensibilidadades diversas, calificadas como hedonistas, promovían manifestaciones artísticas ajenas al corset puritano de las religiones. Por otro lado, la búsqueda de explicaciones más allá de verdades reveladas permitió el avance del conocimiento racional y el surgimiento de escuelas de pensamiento que ponían en duda la permanencia de los mismos dioses. Es reveladora la escena sartriana en la que Júpiter dice a Egisto, rey de Argos: «El secreto doloroso de los dioses y de los reyes es que los hombres son libres. Son libres, Egisto. Tú lo sabes, y ellosn no». Y añade: «Una vez que ha estallado la libertad en el alma de un hombre, los dioses ya no pueden nada contra ese hombre». (Sarte, 1984)

Para aplastar toda disidencia contra el dogmatismo fue necesaria la alianza estratégica entre la religión y la política. Convenía a los intereses de Estado. Acusado de herejía y de pervertir las costumbres, Sócrates es condenado a muerte. Más tarde, la "Academia», fundada por Platón, es clausura por el emperador Justiniano acusándola de ser un foco de paganismo (Blásquez, 2001). Fue la aspiración de Constantino de convertirse en emperador de Oriente y reunificar el imperio bajo su único mandato, lo que lo indujo a oficializar en el Concilio de Nicea al cristianismo como religión del imperio romano. La paradoja consiste en que este hecho, ocurrido después de 325 años de la fecha asignada al nacimiento de Cristo, instituyó la naturaleza del Hijo de Dios y su relación con Dios Padre, la construcción de la primera doctrina cristiana uniforme, el establecimiento de la fecha de la Pascua, y la promulgación del primer Derecho Canónico. (Castillo, 2006)

La fuerza de esta alianza, eficaz también para los pueblos del antiguo Perú, sigue siendo evidente a nivel mundial. George Bush, el presidente de los Estados Unidos de Norteamérica, el hombre más poderoso de la tierra, dijo: «Me conduce una misión de Dios. Dios me dice 'George, ve y lucha contra esos terroristas en Afganistán'. Y 
lo hice. Y luego Dios me dice 'George, ve y termina con la tiranía en Irak'». (The Guardian, 2005)

La eficacia de la alianza entre religión y política necesitaba algo más que las redes de intereses tangibles. Fue necesario, además, advirtiendo el enorme poder de la moral como factor de cohesión social, que las religiones se afianzaran como ideología moral. De ese modo, toda religión, reclamándose como designio moral, impuso su hegemonía sobre los otros campos de la cultura: el conocimiento y el arte, y sobre los otros subsistemas de la gestión social: la economía y la política. Es esta perspectiva, lo que permite la consagración de las grandes religiones y de sus mentores: Buda, Cristo y Mahoma, entre los más destacados.

El poder absoluto que otorga una visión compartida del dogma y la autoridad como práctica social es de larga data, $\mathrm{Y}$ es también de larga data el combate asumido, desde la trinchera opuesta, por artistas, libre pensadores e intelectuales que se dieron la misión de promover horizontes alternativos. En Europa, para que el criterio de verdad se desvincule del dogma, la tradición o la autoridad y, en cambio, se lo relacione con el empirismo, la lógica o la razón, fue preciso el surgimiento de librepensadores. Su entorno era un campo minado: considerados herejes e intrusos fueron condenados a prisión, al destierro, al exilio autoimpuesto, a la muerte.

Esta misión autoasumida de librepensadores de combatir la alianza del dogma con la política permitió el surgimiento del Renacimiento, del Humanismo, y de la Ilustración. Cuando las ideas libertarias fueron asumidas por un considerable número de autores y popularizadas en la literatura, sucede la paulatina transformación de las mentalidades y, en circunstancias concretas, las revoluciones sociales. Con la Revolución Francesa las contradicciones alcanzaron un nuevo nivel: no solo se negaba la existencia de dioses; se cuestionó todo orden político basado en verdades reveladas. Matemáticos (William Kingdon Clifford), filósofos (Denis Diderot, Jean le Rond d'Alembert, Voltaire), literatos (François Rabelais), sentaron las bases del racionalismo y del humanismo como dimensiones alternativas para construir horizontes de sentido. Estos procesos, de acuerdo a Daniel Mornet (1972), en Los orígenes intelectuales de la revolución francesa (1715-1787), muestran el importante papel de la élite que desarrolló las condiciones para que innumerables franceses reflexionaran sobre la necesidad de profundas reformas y en la naturaleza de esas reformas.

Para el contexto inglés, Christopher Hill (1980), señala que, más que una elite educada en cenáculos especiales, los intelectuales se formaron en el mismo proceso formativo de Gran Bretańa, en el que se puede distinguir un primer período signado por triunfos políticos y económicos (la unión pacífica de las coronas de Inglaterra y Escocia, la derrota de España, la subyugación de Irlanda, los comienzos de la colonización de América y la fundación de la Compañía de las Indias Orientales), que fue también la edad de oro de la producción intelectual inglesa. (Hill, 1980, pp. 26-27) 
¿Cuáles son, entonces, los márgenes de acción y cuál la eficacia de cada uno de ellos? Para el caso europeo, Hill señala acertadamente: «El movimiento científico le debía mucho a la tradición independiente de Padua, pero la fermentación intelectual de la Reforma, la actitud escéptica de los reformadores hacia los milagros y las imágenes y algunas de las actitudes personales de Calvino contribuyeron también a la reforma». (Hill, 1980, p. 336). Cabe destacar que Hill no está afirmando que la producción intelectual inglesa y los acontecimientos económicos y sociales actuaban por reflejos condicionados. Su relato da cuenta, más bien, de que el despligue social debe ser entendido como un proceso holístico en el que toda comunidad y sus pensadores, llenos de subjetividad e influidos por hechos objetivos, influyen a su vez sobre los acontecimientos: hay una notable interacción e interdependencia entre ellos. Es en esta perspectiva, que cada tipo de sociedad produce sus propios librepensadores y sus particulares paradigmas. En nuestro país, la guerra con Chile y la depresión social consecuente enervó el talento crítico de Gonzáles Prada; la revolución bolchevique en Rusia y la emergencia de las capas medias en el Perú empataron con el genio racional de Mariátegui. Nuestra época nos remite a un escenario hirviente «de todas las sangres» cuyos múltiples conflictos permitieron el despliegue intelectual de José María Arguedas y de Alberto Flores Galindo.

\section{Qué es ser intelectual}

En un debate periodístico relacionado con la función del intelectual, José Ignacio López Soria indica: "Gustavo Gorriti abusa al atribuir el término 'intelectual', en el mismo sentido, a periodistas y hacedores de opinión y a pensadores como el filósofo Martín Heidegger (...) la filosofía y el periodismo se mueven en mundos diversos que no toleran, sin abuso, ser homologados». (López Soria, 2005).

La respuesta de Gorriti fue inmediata. "Comprendo -dice él-, que entre el Sein und Zeit de Heidegger y El futuro diferente de (Alan) García, hay algunas diferencias. Y comprendo también que el ámbito del periodismo no es, por lo general, el de la ontología. Ello no significa, sin embargo, que sea falaz o abusivo considerar simultáneamente como intelectual tanto al periodista como al filósofo. Ambos lo son, en tanto su labor es la de producir ideas. De diferente tipo, pero ideas al fin, expresadas y expuestas a quienes quieran y puedan entenderlas». (Gorriti, 2005).

Esta polémica, no zanjada aún en la epistemología peruana, tuvo el valor agregado de mostrar las dificultades entre nosotros para acreditar la función del intelectual e incluso para definir su procedencia. Aún más, en un escenario en el que varios expresidentes del Perú, denunciados por lavado de activos, fugan del país, sufren prisión preventiva o son obligados a renunciar, César Hildebrandt advierte la actitud elusiva de los 
intelectuales peruanos frente a estos hechos. Nos pregunta: ¿qué hacen los intelectuales en el Perú? ¿Dónde están sus voces, sus iras, sus ensayos sobre este país, el nuestro, capturado por las mafias? (Hildebrandt, 2018).

Jean Paul Sartre sostenía que en las sociedades modernas la producción del conocimiento y el estudio de los medios de gestión de la sociedad están reservados a un grupo de técnicos (sabios, ingenieros, médicos, abogados, profesores, literatos, etc.). En conjunto, estos técnicos del saber práctico no son todavía intelectuales, pero es entre ellos - y en ninguna otra parte- que los intelectuales se reclutan. ¿Qué diferencia a unos de otros? se pregunta. $\mathrm{Y}$ añade: «el hecho que los intelectuales superponen a su función de expertos del saber práctico, la ideología (particularismo étnico, clasista, de género), que les induce a hacerse guardianes de fines fundamentales: emancipación, humanización del hombre, etc.". (Sartre, 1973, pp. 289-290).

Es esta perspectiva del compromiso la que hace que los intelectuales, a diferencia de los operadores del saber (académicos, ingenieros, escritores), se exijan apalancar el conocimiento hacia dimensiones valorativas para cuestionar el statu quo y reorganizar la sociedad. Cuando Einstein investiga y desarrolla la bomba atómica es básicamente un científico; cuando alerta a la humanidad sobre su uso y promueve la paz mundial, es un intelectual. $Y$ es en este sentido que Michel Foucault precisa que, independientemente de la especificidad de las condiciones de vida y de trabajo (su campo de investigación, su puesto en el laboratorio, las exigencias económicas o políticas a las que se somete o contra las que se revela en la universidad, en el hospital, etc.), el intelectual puede tener una significación general, donde el combate local o específico que desarrolla produce efectos, implicaciones que no son necesariamente profesionales o sectoriales: «No se trata de un combate 'a favor' de la verdad sino en torno al estatuto de verdad y al papel económico-político que juega. Hay que pensar los problemas políticos de los intelectuales no en términos de 'ciencia/ideología' sino en términos de 'verdad/poder' " (Foucault, 1983, p. 53).

Resultan ilustrativas las diversas definiciones sobre el intelectual analizadas por Cornejo Polar (1991): «Detentador del monopolio de la producción del discurso sobre el mundo social» (Bourdieu); «involucrado en la necesidad radical de penetrar más allá de la experiencia concreta y producir los símbolos de valor que permitan influir sobre ellos y transformarlos» (Molnar); "constructor de percepciones globales de los destinos nacionales que los ubican en marcos universales» (Angel Rama); "productor de discursos críticos reflexivos» (Alvin Gouldner). Por nuestra parte, recordamos a Morin: «Ser intelectual es auto-instituirse como tal, es decir darse una misión: una misión de cultura, una misión contra el error, una misión de conciencia para la humanidad» (Morin, 1995, p. 230). 


\section{La misión del intelectual}

La complejidad en definir la misión del intelectual, es una historia de larga data. Julien Benda la vinculó a la producción de paradigmas por individuos solitarios (filósofos, religiosos, literatos, artistas, eruditos), cuya realización exigía de ellos la renuncia a toda pasión. Sin embargo, Benda (1951, p. 165), reconoce que los tiempos han cambiado al intelectual: «Lo crié para ser espiritual en lo carnal; ahora se ha vuelto carnal incluso en el espíritu». La exigencia de Benda de apelar, al mismo tiempo, a la desinteresada actividad de la mente y al renunciamiento de la acción, que convertía al intelectual en estoico anacoreta, no fue posible porque los hechos marcharon a contracorriente de sus deseos: los descubrimientos científicos, los cambios económicos y el despegue del nacionalismo que sentaron las bases de la modernidad, ligaron al intelectual con la sociedad en tal magnitud y con tanta cercanía que no pudo eludir el papel de actor, destacadísimo y conflictuado, en la construcción del 'proyecto moderno'.

Efectivamente, el proceso histórico de la modernidad interpeló al intelectual y lo indujo a ser parte esencial de los nuevos tiempos en una espiral en la que él y su obra crecían y se retroalimentaban permanentemente dentro de un escenario en el que todas las verdades eternas empezaban por disolverse bajo la acción de intrépidos navegantes, audaces comerciantes e innovadores empresarios. Al respecto, Marx (2000) señala: «En lugar del antiguo aislamiento y la amargura de las regiones y naciones, se establece un intercambio universal, una interdependencia universal de las naciones. Y esto se refiere tanto a la producción material, como a la intelectual. La producción intelectual de una nación se convierte en patrimonio común de todos. La estrechez y el exclusivismo nacionales resultan de día en día más imposibles; de las numerosas literaturas nacionales y locales se forma una literatura universal». Fue necesario, entonces, un cambio radical no solo en los contenidos sino también en las formas de la producción intelectual conocidas hasta ese entonces.

Pero no en todas las culturas han surgido intelectuales con la potencia manifiesta como la que advertimos en las pueblos de Occidente. Reconociendo que en Europa surgieron ciertos fenómenos culturales cualitativamente diferentes a los ocurridos en los pueblos orientales, que parecen marcar una dirección evolutiva de universal alcance y validez, Max Weber (1987), anota: «Si el capitalismo moderno implica la confluencia de los medios técnicos de cálculo del trabajo (que sí existían en Oriente), como de un derecho previsible y una administración guiada por reglas formales (que surgió en Occidente)... ¿A qué se debe la existencia de tal derecho?, ¿por qué los intereses capitalistas no actuaron en el mismo sentido en China?, ¿por qué no orientaron el desarrollo científico, artístico, político y económico por el mismo camino de la racionalización que es propio en Occidente?». Y, advirtiendo que las pistas llevan a un «racionalismo» específico y peculiar de la cultura occidental, concluye que la respuesta no es fácil: «La 
ruptura con el tradicionalismo económico parece ser un momento excepcionalmente favorable para que el espíritu se incline a la duda ante una tradición religiosa (la católica) y acabe por rebelarse ante las autoridades tradicionales (la aristocracia)» (Weber, 1980, p. 8).

Eso explica que los intelectuales, atrincherados en la razón que provenía del libre y democrático ejercicio de la ciencia, pusieran en la mira desacreditar la cultura feudal asentada sobre dogmas y linajes hereditarios. De esa manera, el movimiento de la investigación científica y el de la clase burguesa en ascenso se correspondían. Sus triunfos consagraron la cultura occidental y sus discursos fundantes: a) del que legitima la función legisladora del conocimiento y le confiere una función totalizadora (Hegel); y, b) del que legitima la moral autónoma como fundamento racional-práctico para la libertad del sujeto razonante (en Kant), o del sujeto trabajador (en Marx).

$\mathrm{Al}$ identificar la razón y la ciencia como fuentes de verdad, el intelectual se enfrentó a los guardianes de dogmas y a sus verdades reveladas. Al proponer la necesidad del Estado-nación y de su soberanía sobre el mercado interno se enfrentó a las Estados multinacionales construidos sobre doctrinas universalistas (los estados feudales cristianos, islámicos, etc.). Al sustentar la esencia popular del poder se enfrentó a toda monarquía y jerarquía dominantes. Por ello, la función de opositor que asume en un reto que lo hace vivir al filo de la navaja.

\section{Campo intelectual y opinión pública}

Pregonar la libertad y la razón a sus contemporáneos exige de los librepensadores producir su propia libertad frente a todo mecenazgo, a todo canon escolástico, estético y moral. Para demostrar, desde su propia experiencia personal, que no habría vuelta atrás en la lucha para influir en sus contemporáneos, Kant, en la introducción de la Crítica a la razón pura, agradece al príncipe, cuyo despotismo demolerá en el contenido de su obra.

A fines del siglo xix los librepensadores fueron calificados, por primera vez, como «intelectuales». Este calificativo, empleado por los representantes del poder en Francia, definía despectivamente a todo ideólogo que vivía en los márgenes de la sociedad estamental, sin tradición orgánica, y que atentaba deliberada y peligrosamente contra el patriotismo y el catolicismo que sostenían la nación francesa. El anatema fue dirigido, sobre todo, a Emilio Zola, Octave Mirbeau y Anatole France por haber denunciado la condena de prisión perpetua al capitán Alfred Dreyfus, de origen judío, acusado del delito de espionaje a favor de Alemania, no obstante haberse descubierto al verdadero traidor, el comandante Ferdinand Esterhazy.

El que la opinión pública francesa apoyara la denuncia de sus «intelectuales» favoreció la libertad de Dreyfus y, sobre todo, prestigió socialmente al intelelctual como 
creador de horizontes de sentido e indujo que éste, como lo indica Bourdieu, no solo se interese en elaborar síntesis epistemológicas para explicar el mundo y promover el cambio, sino, además, en desarrollar una esfera propia de empoderamiento. Para ello fue necesario, a medida que los campos de la actividad humana se diferenciaban, que un orden propiamente intelectual, dominado por un tipo particular de legitimidad, se definiera por oposición al poder económico, al poder político y al poder religioso, es decir, a todas las instancias que podían pretender legislar en materia de cultura en nombre del poder o de una autoridad que no fuera propiamente intelectual. (Bourdieu, 1967).

En la medida que aparecieron instancias específicas de selección y de consagración propiamente intelectuales y colocadas en situación de competencia por la legitimidad cultural, la historia de la vida intelectual y artística de Occidente, según Bourdieu, permite ver de qué manera el «campo intelectual» (y al mismo tiempo lo intelectual opuesto, por ejemplo, a lo ilustrado) se ha integrado progresivamente en un tipo particular de sociedades históricas. En este panorama, la prensa y la opinión pública son dos factores que juegan a favor del empoderamiento de los intelectuales. Advertidos del poder de estos factores, a los que tienen que enfrentarse para la aceditación social de su obra, los intelectuales terminarán reconociendo que existen cualidades que les llegan solo por los juicios de los demás, de tal modo que, como lo señala Habermas (1961, p. 62): "por medio de esta representación social, que tiene la opacidad y la necesidad de un dato de hecho, la sociedad interviene, en el centro mismo del proyecto creador, invistiendo al artista de sus exigencias o sus rechazos, de sus esperanzas o su indiferencia». Efectivamente, de acuerdo a Habermas, la importancia de estos factores es de tal magnitud que toda la vida social ha terminado por convertirse en asunto de interés público, haciendo de toda ella una zona crítica en el sentido que reclama la crítica de un público raciocinante.

Atrincherados en su área de influencia cultural, sobre la base del conocimiento, los intelectuales han expandido su influencia hacia las otras dimensiones de la gestión social: la política, la economía, el medio ambiente. Expertos en la reflexión crítica sobre la realidad natural y social, han influido sobre amplios sectores de la opinión pública mundial que ya no aceptan las verdades reveladas y que no solo tiran por la borda el origen divino de la realeza, sino que terminan oponiéndose a su vigencia política. Otros logros sustantivos en la conciencia pública fueron el desmantelamiento de la racionalidad instrumental de la política económica, la expansión de discursos formativos a favor de las comunidades nacionales, el reconocimiento de los derechos humanos, la defensa del medio ambiente. Todos ellos tienen en el ensayo ("género híbrido entre filosofía, literatura, periodismo y sociología»), su medio de expresión más adecuado. 


\section{Perú al pie del orbe}

Si la actuación de los intelectuales marca a fuego los alcances y contenidos del proyecto civilizatorio moderno, basado en la apreciación hegeliana de que una sociedad es racional (léase moderna) cuando es fruto de acuerdos intersubjetivos de sus actores, ¿cómo se expresa el ejercicio intelectual en un país tan fracturado como es el Perú? ¿Cómo se compagina la ruta histórica de la intelectualidad global con la experiencia intelectual en el Perú?

No se compagina. La producción intelectual peruana, fundamentalmente, no ha logrado aún, de manera orgánica, construir los horizontes de sentido que reclaman nuestros pueblos para escapar de estas democracias con desigualdad y con miseria. Menos aún si a ello se añade la discriminación étnica y el racismo de las clases propietarias contra millones de hombres y mujeres de las culturas andinas y amazónicas descalificadas por «arcaicas». Ello obliga a lecturas diferentes de la acción social que si bien no atenta (todavía) contra la existencia hegemónica de los intelectuales afines a la modernidad, si advierte la precariedad de sus discursos cuando estos pretenden, en postulados universalistas e integradores, colonizar el mundo de la vida y encapsular la extraordinaria diversidad de las culturas en el Perú. La situación social resultante es el rencor permanente.

En este conflictuado escenario, tenemos a favor nuestros propios herejes, libre pensadores e intelectuales que, sobre la base del intelectualismo moral que reclamaba Sócrates, han construido y siguen haciéndolo, los discursos que develan las terribles consecuencias de nuestra herencia colonial y de los efectos de la actual globalización que no permiten a nuestros pueblos promover la afinidad electiva entre interculturalidad, economía innovadora, democracia participativa y sostenibilidad ambiental. Entre ellos, destacan: Mariátegui, González Prada, Arguedas, Flores Galindo, Aníbal Quijano.

\section{Referencias}

Benda, J. (1951). La traición de los intelectuales.: Edit. Ercilla. Santiago de Chile.

Bourdieu, P. (1967). «Campo intelectual y proyecto creador». En: Problemas del estructuralismo. Siglo XXI editores. México.

Blázquez, J. M. (2001). «La Academia de Atenas como foco de formación humanística para paganos y cristianos. Los casos de Juliano, Basilio y Gregorio Nacianceno». Gerión. Revista de Historia Antigua (19): 595-628. ISSN 0213-0181.

Castillo Pascual, P. (2006). Año 312. Constantino: emperador, no cristiano. Laberinto. Madrid: ISBN 8484834085. 
Cornejo Polar, J. (1993). Intelectuales, artistas y Estado en el Perú del siglo XX. Lima: Edic. Universidad de Lima, Cuadernos de Historia XVII.

Foucault, M. (1983). El discurso del poder. México: Folios ediciones.

Gorriti, G. (2005). «Mentiras, miedos y verdades». La República: 20 de marzo de 2005. Lima.

Habermas, J. (1961). Historia y crítica de la opinión pública. Madrid: Edit. Tecnos.

Hildebrandt, C. (2018). Hildebrandt en sus trece. 7 de setiembre de 2018. Lima.

Hill, C.(1980). Los orígenes intelectuales de la revolución inglesa. Barcelona: Ed. Crítica.

López Soria, J.(2005). En «Los intelectuales» de Gorriti». La República: 19 de marzo de 2005). Lima.

Marx, C. (2000) El manifiesto comunista. Ediciones elaleph.com. https://es-la.facebook.com/ pg/elalepheditores/about/?ref=page_internal

Morin, E. (1995). Mis demonios. Madrid: Edit. Kairos.

Mornet, D. (1972). Los orígenes intelectuales de la revolución francesa 1715-1787. Buenos Aires: Edit. Paidós.

Platón (2003). Diálogos. Volumen I: Protágoras. Madrid: Editorial Gredos.

Sartre, J. (1973). «La defensa de los intelectuales», en Alrededor del 68. Buenos Aires: Edit. Losada.

SARTre, J. (1984). Las moscas. Madrid: Alianza Editorial S.A.

The Guardian (2005). Citado en http://www.rebelion.org/noticia.php?id=86281 7-10-5

Weber, M. (1987). La ética protestante y el espiritu del capitalismo. Madrid: Edit. Economía y Sociedad/ Fondo de Cultura Económica. 